\section{Lymphoedema in the Observation and Biopsy Arms of MSLT-1}

\section{TO THE EDITORS:}

Your journal has recently published an editorial and a leading article on the complications of early versus delayed lymphadenectomy in the first Multicenter Selective Lymphadenectomy Trial (MSLT-1). ${ }^{1,2}$

To date, MSLT-1 has not shown any difference in overall survival or any valid difference in disease-free survival between the observation and biopsy arms of the trial. ${ }^{3}$ Hopefully any difference in distant disease-free survival will be described in the fifth and final report. Meanwhile, it is claimed that morbidity is lower and length of stay shorter in patients who have early lymphadenectomy. ${ }^{2}$

Faries et al. state that the data on acute and chronic morbidity in MSLT-1 was collected prospectively. ${ }^{2}$ According to a previous publication that is not correct. ${ }^{4}$ Morton et al. have stated clearly that the complications of delayed lymphadenectomy in the observation arm were not prospectively evaluated (page 309, column 2, para 4). ${ }^{4}$ Therefore, if any data were collected retrospectively by Faries et al., this should be stated because of the possibility of selection or observer bias. For example, the assessment of lymphedema as mild, moderate, or severe is, in part, subjective, but the number of days spent in the hospital is an objective measurement. Therefore, if this data were collected prospectively, why were significantly fewer patients evaluated for length of stay than for lymphedema?
Finally, both papers fail to acknowledge that in melanoma, sentinel lymph node biopsy alone can cause lymphedema. ${ }^{1,2}$ Estourgie et al. describe mild but persistent lymphedema at 6 years in $12 \%$ of such patients. ${ }^{5}$ If the late results of MSLT-1 are similar, then overall, more patients entered into the biopsy arm of MSLT-1 would have lymphedema than patients entered into the observation arm given that approximately $80 \%$ of patients who undergo sentinel lymph node biopsy for melanoma are sentinel lymph node-negative.

\section{J. Meirion Thomas, FRCS}

Surgical Oncology, Royal Marsden Hospital, London, UK e-mail: meirion@ roseway.demon.co.uk

Published Online: 20 July 2011

(C) Society of Surgical Oncology 2011

\section{REFERENCES}

1. Callender GG, McMasters KM. Early versus delayed completely lymphadenectomy in melanoma: insight from MSLT-1. Ann Surg Oncol. 2011;18:306-8.

2. Faries MB, et al. The impact on morbidity and length of stay or early versus delayed complete lymphadenectomy in melanoma: results of the Multicenter Selective Lymphadenectomy Trial (1). Ann Surg Oncol. 2010;17:3324-9.

3. Thomas JM. Concerns relating to the conduct and statistical analysis of the Multicenter Selective Lymphadenectomy Trial (MSLT-1) in patients with melanoma. J Plast Reconstr Aesthet Surg. 2009;62:442-6.

4. Morton DL, et al. Sentinel node biopsy for early-stage melanoma: accuracy and morbidity in MSLT-1, an international multicenter trial. Ann Surg. 2005;242:302-11.

5. Estourgie SH, Nieweg OE, Valdes-Olmos RA, Hoefnagel CA, Kroon BB. Review and evaluation of sentinel node procedures in 250 melanoma patients with a median follow-up of 6 years. Ann Surg Oncol. 2003;10:681-8. 